\section{Espacio público y acción colectiva: análisis de los procesos de disputa por la mejora del hábitat en dos barrios periféricos de la Ciudad de la Plata}

\author{
Sandra Valeria Ursino ${ }^{1}$ \\ ORCID: https://orcid.org/0000-0002-6136-5105 \\ Correo electrónico: sandraur@hotmail.com
}

\section{Public space and collective action: analysis of the processes of dispute for the improvement of the habitat in two peripheral neighbourhoods of the City of la Plata}

Juan Ignacio Rojas Chediac ${ }^{1}$

ORCID: https://orcid.org/0000-0001-7518-3778

\author{
Maira Muiños Cirone ${ }^{1}$ \\ ORCID: https://orcid.org/0000-0001-6341-3150
}

${ }^{1}$ Centro Interdisciplinario de Estudios Complejos, FAU, Universidad Nacional de La Plata, La Plata, Argentina.

El financiamiento de la presente investigación fue realizado a través del otorgamiento de becas por el Consejo Nacional de Investigaciones Científicas y Técnicas de Argentina (CONICET). En tanto que Ursino posee una beca posdoctoral y Rojas Chediac y Muiños Cirone, becas doctorales.

\begin{abstract}
Resumen
En este artículo, se presenta la relevancia que adquirió el espacio público urbano en relación con dos acciones colectivas, en la disputa por la mejora del hábitat en sectores periféricos de la ciudad de La Plata. Uno en San Carlos, posterior a la inundación del 2 de Abril de 2013; y el otro, en Los Hornos, por la baja en el suministro de energía en el año 2016. Ambos acontecimientos actuaron como disparadores que modificaron los usos y apropiaciones que realizaron del espacio público los/as habitantes de cada barrio. A partir de las condiciones críticas del hábitat popular, por el deterioro de infraestructura, como equipamiento social y habitacional, el espacio público urbano fue utilizado por vecinos, vecinas y organizaciones sociales para realizar asambleas. En ambos casos, las demandas planteadas generaron procesos de organización y participación activa en la toma de decisiones, que llevó a preguntarnos cómo se establecen vínculos simbólicos y materiales con un espacio urbano determinado, y qué importancia adquieren en la organización barrial. Asimismo se indagó en su incidencia en la participación ciudadana de los/as habitantes, como también en sí son prácticas que persisten en el tiempo o si pasado el momento conflictivo, desaparecen.
\end{abstract}

Palabras clave

Espacio público urbano, mejoramiento del hábitat, acción colectiva, asamblea barrial

\begin{abstract}
This article presents the relevance that urban public space acquired in relation to two collective actions, in the dispute over habitat improvement in peripheral sectors of the city of La Plata. One in San Carlos, after the flood of April 2, 2013; and the other, in Los Hornos, due to the drop in energy supply in 2016. Both events acted as triggers that modified the uses and appropriations of public space by the inhabitants of each neighborhood. Due to the critical conditions of the popular habitat, due to the deterioration of infrastructure, such as social and housing equipment, urban public space was used by neighbors and social organizations to hold assemblies. In both cases, the demands made generated processes of organization and active participation in decision making, which led us to ask ourselves how symbolic and material links are established with a given urban space, and what importance they acquire in neighborhood organization. We also investigated their impact on citizen participation, as well as whether these practices persist over time or whether they disappear once the conflict has passed.
\end{abstract}

\section{Keywords}

Public space, habitat improvement, collective action, neighborhood assembly 


\section{Introducción}

El 2 de Abril de 2013, la ciudad de La Plata -capital de la Provincia de Buenos Aires-Argentina- sufrió una de las inundaciones más trágicas de su historia. Aproximadamente en un lapso de tres horas cayeron 302 milímetros de lluvia a raíz de un temporal calificado de "extraordinario" por algunos expertos de la UNLP1. Esto generó la organización en asambleas de los/as vecinos/as afectados/as en varios barrios de la ciudad, uno de ellos, en la delegación de San Carlos. Asimismo, con una escala de afectación urbana menor, la baja en el suministro de energía en el año 2016 dejó sin electricidad por casi 40 días a más de 900 familias en el barrio Las Palmeras de la delegación de Los Hornos. Ambas delegaciones son periféricas al casco fundacional, cuyo desborde se ha consolidado debido a la expansión urbana y al incremento poblacional. Los acontecimientos antes mencionados, modificaron drásticamente la vida cotidiana de los/as habitantes, y pusieron en crisis nuevamente la idea de una ciudad planificada y organizada urbanísticamente. Con escalas de afectación dispares, ambos eventos mostraron una vez más, la desigualdad social y urbana que padecen los sectores populares platenses.

A partir de estos hechos que originaron la participación barrial, junto a las condiciones estructuralmente críticas del hábitat popular -por el deterioro tanto de infraestructura como de equipamiento social y habitacional- el espacio público urbano fue utilizado activamente por vecinos, vecinas y organizaciones sociales para realizar reuniones asamblearias. En ambos casos, las demandas planteadas en estos encuentros giraron principalmente alrededor del mejoramiento barrial, yendo más allá del daño causado, buscando organizarse y participar activamente en la toma de decisiones. Por tales motivos, en este trabajo nos centramos en los usos y apropiaciones que realizaron del espacio público urbano los/as vecinos/as de ambos barrios durante los procesos organizativos. Ambos escenarios llevaron a preguntarnos ¿cómo se establecen vínculos simbólicos y materiales con un espacio urbano determinado?, y ¿qué importancia adquieren en la organización barrial?

Estos interrogantes nos llevan a plantear la hipótesis de que las acciones colectivas visibilizan problemáticas naturalizadas construyendo demandas por el mejoramiento barrial, y en los casos de estudio, los hechos disruptivos potenciaron la participación y la apropiación de espacios público urbano que previamente eran escasamente utilizados. De esta manera, las acciones colectivas dan cuenta de una transformación del espacio urbano tanto en términos materiales como simbólicos, modificando los significados de habitar el barrio. El objetivo del presente artículo, es presentar los procesos materiales, simbólicos y políticos que atraviesan dos barrios populares de la periferia platense ante las demandas de mejoramiento barrial, e indagar qué impacto tiene en la organización barrial y en la apropiación del espacio público de los vecinos/as.

En una primera parte, se plantean las líneas de análisis con las cuales se aborda la investigación: espacio público y acción colectiva. En una segunda parte, se desarrolla la reconstrucción material-histórica del territorio donde se encuentran los casos de estudio seleccionados, se desarrolla la metodología implementada y se analiza mediante la elaboración cartográfica la expansión urbana hacia las periferias. Finalmente, se indaga en las experiencias vividas por los/as vecinos/as de ambos barrios, recolectando los significados otorgados a las asambleas barriales y los procesos de organización popular en el espacio público. También se analiza, su incidencia en la participación ciudadana de los/as habitantes, como también en sí son prácticas que persisten en el tiempo o si pasado el momento conflictivo, se agotan. Para ello

1 Tal como fue el caso de las declaraciones del Ing. Pablo Romanazzi que adquirió gran visibilidad pública a partir de este acontecimiento. En el libro Genealogía de una tragedia. Inundación de La Plata, 2 de abril de 2013 (Morosi y Romanazzi, 2013), narran las causas naturales y humanas que llevaron a vivir este fenómeno meteorológico de un modo trágico, que puso en evidencia las debilidades de la gestión municipal para enfrentar fenómenos pluviales extremos, que fueran advertidas en detalle, desde hace más de tres décadas, por los expertos en la materia de la Universidad Nacional de La Plata. 
se parte de una perspectiva constructivista que permite abordar las distintas relaciones que se ponen en juego dentro de la ciudad, y más específicamente en/con/desde el espacio público urbano.

\section{Espacio público y acción colectiva: elementos conceptuales para pensar los procesos de apropiación del espacio}

En los últimos años, las ciudades se han convertido en el escenario predilecto para la conformación de acciones colectivas (Harvey, 2014), donde la mejora de la vivienda y los bienes comunes son sólo dos ejemplos de las demandas de las nuevas luchas urbanas (Martí Costa Bonet Martí, 2008). La acumulación por desposesión (Harvey, 2004), conjuntamente con el urbanismo neoliberal (Theodore, Peck y Brenner, 2009), generaron un desplazamiento en la lucha urbana del lugar de producción al espacio urbano en general y a su esfera pública en particular. En este contexto, tal como expresa Delgado (2011) el espacio público urbano se encuentra en una tensión por la definición de sus características. Según el autor, por un lado, encontramos una visión idealista de que el espacio público es un lugar para el diálogo y el encuentro, donde cualquier persona puede circular libremente, supone que la ciudad está libre de conflictos y que el ideal de espacio público es un lugar para el consenso y la participación ciudadana. Por otro lado, el espacio público muchas veces es observado desde una perspectiva tecnicista y academicista desde la arquitectura, el urbanismo y el diseño urbano, considerándolo como un vacío urbano al que hay que llenar y de este modo pierde su capacidad política y social.

Esta idea urbanizadora asocia el espacio público como un vacío urbano que acompaña el entorno construido, pero no tiene conexión posible con presupuestos políticos e ideológicos, principalmente si está vinculado a reformas o revitalizaciones urbanas o zonas industriales obsoletas y en proceso de reconversión. Entonces el concepto aparece en las retóricas político-urbanísticas y forma parte de las agendas gubernamentales, pero no hay una definición acabada del mismo. Incluso muchas veces el espacio público solo aparece asociado al de plaza y calle.
Esto último, es retomado en el trabajo de Jacobs (2011), quien discute con los tecnócratas urbanos y propone activamente la recuperación de la calle y el barrio para terminar con los lugares inseguros de la ciudad.

Las visiones mencionadas entran en tensión cuando se enfrentan a la situación actual, donde predomina el conflicto social, el acceso desigual y la inseguridad (Boy, 2018; Carrión M., 2016; Duhau, 2009; Segura, 2009; Sznol, 2007; Torres, 2011). De esta manera, el espacio es el producto de una sociedad determinada, una parte integral de la construcción material y la estructuración de la vida social, una interpretación de las conexiones entre el espacio físico, cognitivo y social (Soja, 1985). El espacio público urbano, es entonces, interpretado como medio (supuesto) y como resultado (corporización) de la estructura social y de sus relaciones. Entonces, el espacio no es meramente la arena en la que los conflictos y las disputas se expresan, sino el dominio dentro y a través del cual las relaciones son constituidas (Gregory, 1984). En otras palabras, el espacio público urbano es el reflejo de las relaciones de poder (de clase, género, etnia, raza, etc.) y sólo tienen una existencia social en la medida en que existen espacialmente. Ellas se proyectan en el espacio, se inscriben a sí mismas en un espacio a medida que se producen, de otra manera quedarían en una pura abstracción (Lefebvre, 1976). Los elementos físicos y simbólicos del espacio operan disciplinando a los sujetos, estableciendo restricciones al desplazamiento, imponiendo determinadas circulaciones, sujetando los encuentros sociales, es decir, revelando una estructura de poder, la cual se expresa y ejercita (Foucault, 1992). Como consecuencia, la segregación socio espacial, producto del sistema capitalista-patriarcal, evidencia distintas formas de concebir lo público del espacio, en su mayoría encaminadas a la individualización, fragmentación y jerarquización de éste.

En palabras de Bourdieu:

los agentes sociales se constituyen como tales en y por la relación con un espacio social [...] y también las cosas en tanto los agentes se apropian de ellas, y por ende las constituyen como propiedades, están situados en un lugar del espacio social que puede 
caracterizarse por su posición relativa con respecto a los otros lugares y por la distancia que lo separa de ellos. [...]. La posición del agente en el espacio se expresa en el lugar del espacio físico en el que está situado y por la posición relativa que sus localizaciones temporarias y sobre todo permanentes ocupan con respecto a las localizaciones de los otros agentes.” De este modo, la posición que se ocupa en la estructura y espacio social adquiere importancia para analizar las acciones colectivas en el espacio urbano. (2001, p. 150)

De esta manera, la apropiación de cada grupo social con un espacio urbano delimitado es la consecuencia de un entramado relacional complejo, ubicándose cada sujeto en un espacio social determinado. Dicha ubicación en la ciudad se da en términos físicos y simbólicos, constituyendo una identificación con el lugar y con el proceso social que se lleva adelante, por ende, con el grupo social en el que se reconoce. Son los capitales, tanto económicos, culturales, sociales y simbólicos, los que determinan el lugar que ocupa cada individuo en la ciudad. Por otro lado, Harvey (1989; 2004) elabora dos categorías para identificar cómo es dicha apropiación. Por un lado, el concepto de apropiación del espacio, que examina la manera en la cual el espacio es usado y ocupado por los/as individuos/as, clases u otros grupos. Por otro, el dominio del espacio que refleja la organización de sectores poderosos que dominan la organización y producción del espacio de manera de ejercer un mayor grado de control sobre el modo en el cual el espacio es apropiado por ellos mismos u otros grupos.

\section{El otro espacio público y sus significados en los procesos de acción colectiva}

A la discusión inicial, se torna necesario confrontarlas con una visión contrahegemónica donde, bajo una mirada foucaultiana del poder (Foucault, 2009), los espacios públicos urbanos además de ser lugares de opresiones, también son utilizados para desafiar el poder. Proporcionan un sitio de acción para darle voz a los/as excluidos/as, dominados/as y oprimidos/as en la sociedad, brindando entonces el potencial de desafiar y subvertir el poder dominante, y por eso, forma parte esencial de una política de resistencia articulada a través de acciones colectivas (Chapman, 2006; Oslender, 2002), entendiéndolas como actos que emprende un grupo de individuos para alcanzar un interés común. Estos intereses compartidos requieren recursos combinados y consisten en episodios de conflictos o de cooperación. Dependientes siempre de relaciones previas, los participantes están negociando incesablemente, improvisando y utilizando la presión del grupo (Tilly, 2000).

En esta línea, la acción colectiva es considerada resultado de intenciones, recursos y límites, con una orientación construida por medio de relaciones sociales dentro de un sistema de oportunidades y restricciones. Por lo tanto, no puede ser entendida como el simple efecto de precondiciones estructurales, o de expresiones de valores y creencias. Los individuos, actuando conjuntamente, construyen su acción mediante inversiones organizadas. Se definen en términos cognoscitivos, afectivos y relacionales el campo de posibilidades y límites que perciben, mientras que, al mismo tiempo, activan sus relaciones para darle sentido al estar juntos/as y a los fines que persiguen (Melucci, 1999).

En este sentido, son los procesos colectivos que se abordan desde, con y en el espacio público, donde la acción colectiva constituye una dimensión activa que puede transformar los vínculos entre individuos a partir del conocimiento y reconocimiento entre sí y con otros actores, llevando a nuevos pactos de interacción social (Rainero, 2014). A su vez, Fenster (2010) en su interpretación de la apropiación que los/as ciudadanos/as pueden realizar del espacio público, encuentra que la clave de este proceso está en la participación ciudadana, ya que las prácticas cotidianas de apropiación y reapropiación del espacio se transforman en el medio a través del cual se produce el encuentro y el cuestionamiento de la noción hegemónica de ciudadanía.

En la misma dirección Harvey (2008, p.23) entiende que el espacio público sólo puede pertenecer al "público" a través de un proceso más amplio de empoderamiento político y económico que lleve a los/as menos privilegiados/as a 
tener una voz más activa en cómo se destina el excedente urbano, es decir, los/as menos privilegiados/as deben ejercer efectivamente el derecho a la ciudad, el cual "no es simplemente el derecho de acceso a lo que ya existe, sino el derecho a cambiarlo a partir de nuestros anhelos más profundos”. En correlato con esta manera de entender el espacio, Borja expresa:

Sin espacio público potente, integrador socialmente, articulador física y simbólicamente, la ciudad se disuelve, la democracia se pervierte, el proceso histórico que hace avanzar las libertades individuales y colectivas se interrumpe o retrocede, la reducción de las desigualdades y la supremacía de la solidaridad y la tolerancia como valores ciudadanos se ven superados por la segregación y la codicia, por el egoísmo y la exclusión. (2014, p.111)

De esta manera, los grupos circunscritos en una situación de dominación son los que llevan adelante los procesos de resistencia en el territorio, y quienes luchan por la mejora de las condiciones del hábitat. Como afirma Kowarick (1996), no importa mayormente la magnitud de la explotación, expoliación y opresión, sino el significado que los grupos atribuyen al proceso organizativo; a su vez, es la subjetividad social en la producción simbólica realizada por los actores que viven, interpretan y elaboran discursos sobre una determinada situación concreta las que posibilitan la cohesión social, y por ende, una mayor capacidad de presión. Los significados actúan como principios generadores y organizadores de prácticas y representaciones, y es lo que permite a los/as individuos/as orientarse en su espacio social y adoptar prácticas que están en acuerdo con su pertenencia social (Bustos Cara, 2005).

De este modo, los sentidos y significados que se construyen respecto a una situación de conflicto requieren un tiempo de proceso y aprehensión necesario para su internalización y reconocimiento como parte de un colectivo. Sin embargo, nos atrevemos afirmar que este sentido de pertenencia es fundamental para todo proceso de organización y logra materializarse con la acción concreta en el territorio, y en el espacio público en particular.

\section{Diseño metodológico}

El diseño de la investigación se abordó desde el estudio de caso como estrategia de análisis por las características "paradigmáticas y ejemplificadoras" (Marradi, Archenti y Piovani, 2010, p.241) que ofrecen los barrios seleccionados respecto a la situación del tejido barrial en La Plata. Se desarrolló una estrategia de estudio de caso colectivo que nos permitió observar por sus componentes similares en cuanto a condiciones socioeconómicas y urbanas, cómo eventos disruptivos de la cotidianeidad -la inundación y el apagón- actuaron como disparadores de la acción colectiva en barrios de Los Hornos y San Carlos.

La metodología utilizada fue mixta basada en el análisis de datos cualitativos y cuantitativos. Se realizó una caracterización de la conformación histórica y urbana de la ciudad de La Plata, y mediante la elaboración de cartografía propia se mostró el crecimiento desigual y desmedido que tuvo la ciudad hacia las periferias. Para abordar la dimensión simbólica y política de estos procesos participativos, se recuperó el punto de vista de los/las sujetos, utilizando como herramienta el análisis de los relatos y las estrategias de participación en las asambleas. En esta dirección, la principal técnica de recolección de datos fueron las entrevistas en profundidad realizada a los/as vecinos/as de las delegaciones estudiadas y a referentes barriales. Las mismas fueron elaboradas con preguntas semiestructuradas para guiar y direccionar el diálogo sobre las principales variables de análisis: apropiación y usos del espacio público, organización popular, y disputas políticas.

El acceso a los barrios fue por medio de la participación de quienes elaboran el presente trabajo, en las organizaciones que conformaron -junto a vecinos/ as- las acciones colectivas presentadas en los casos de estudio. Se realizaron 12 entrevistas en profundidad a vecinos/as y referentes de las asambleas barriales. E1 rango etario de las personas entrevistadas es de 30 a 57 años, en su mayoría mujeres con fuerte participación en los procesos asamblearios y en la organización vecinal por el mejoramiento barrial. El trabajo de campo se realizó durante los años 2014-2019 y se complementa 
con observación participante, mapeos colectivos, asistencia a las asambleas, y registro fotográfico, con el fin de visualizar las principales características de los elementos urbanos del espacio público, sus usos cotidianos y su apropiación simbólica.

Por medio del análisis de datos cuantitativos del Censo Nacional 2010 (INDEC, 2010), se caracterizó a la población de ambas delegaciones en función a condiciones de NBI, al nivel de estudio alcanzado, nacionalidad y condición laboral; lo cual permitió vincular clase social con lugar de residencia.

\section{Problemática y estado del arte}

El crecimiento urbano extendido, desigual e insostenible que ha tenido la ciudad de La Plata en los últimos 20 años, ha generado una extensa bibliografía sobre las desigualdades socioterritoriales (Garnier, 1992; Frediani, 2009; Segura, 2011, 2012, 2013), que nos muestran la consolidación de un proceso urbano segregador y elitista desde su fundación a la actualidad. A su vez, este tipo de fenómeno ha sido ampliamente abordado desde los estudios latinoamericanos por diversos autores (Duhau, 2013; Eilbaum y Villalta, 2002; Rodríguez Vignoli, 2001; Soldano, 2008, 2012) que nos permiten abordar la segregación socio espacial de los barrios analizados a partir de criterios socioeconómicos.

En esta línea de análisis, en la cual se enmarca la presente investigación, se observa que la producción tanto material como simbólica mencionada, producto de las relaciones de poder, genera usos y apropiaciones diferenciadas del espacio público. La jerarquización producida en el acceso a la ciudad, se puede observar en la actualidad pero es algo constitutivo desde la fundación de La Plata. A partir de lo mencionado, se abordarán dos instancias para comprender la conformación actual de los casos de estudio. La primera, de carácter histórico, indagando en la configuración de las periferias de la ciudad, desde sus inicios hasta la actualidad. Una segunda, a partir del Censo Nacional de 2010, donde se explorara las condiciones socioeconómicas actuales. Ambas instancias proponen comprender el espacio urbano desde una perspectiva crítica, para finalizar con un abordaje síntesis de ambos casos de estudio.

\section{El surgimiento de las periferias en el partido de La Plata}

El origen de la ciudad de La Plata contiene la particularidad de haber sido proyectada, bajo ideas higienistas, previamente a su construcción. Este hecho generó un imaginario urbano asociado a una planificación ordenada pero la conformación poblacional y el crecimiento de la misma, en su mayoría, promovieron la segregación socio espacial. En este sentido, se realiza un recorrido histórico de la ciudad de La Plata, desde su fundación a la actualidad, observando las transformaciones territoriales asociadas y condicionadas por la matriz económica y políticas del país.

En 1882 se concreta la fundación de la nueva capital de la Provincia de Buenos Aires, con un plan urbano novedoso que contenía grandes avenidas y diagonales, plazas y parques cada seis cuadras y la Avenida Circunvalación que buscaría delimitar lo urbano y lo rural. Esta primer imagen de la ciudad se desestabiliza conjuntamente con la creación cuando, durante el modelo agroexportador, el aporte migratorio constituye la base poblacional de la ciudad, la cual se radicó fundamentalmente en áreas periféricas debido a la especulación sobre las tierras urbanas dotadas de servicios en el casco fundacional (Frediani, 2010) (Figura 1). La expansión estuvo centrada principalmente en dos sectores con perfiles socioeconómicos diferenciados: por un lado, sobre los corredores que unían La Plata a la Capital del País, mediante viviendas secundarias, y por el otro, en la zona sudoeste, a través de viviendas permanentes vinculadas a la actividad productiva (Ravella Giacobbe, 2005). De esta manera, fue la producción de ladrillos en la primera periferia que dio a esa zona el nombre de Los Hornos, y los procesos de especulación inmobiliaria surgidos tempranamente, los que promovieron el proceso de suburbanización precoz y de desestructuración de la traza urbana (Garnier, 1992). 
Figura 1

La Plata, $1882-1930$

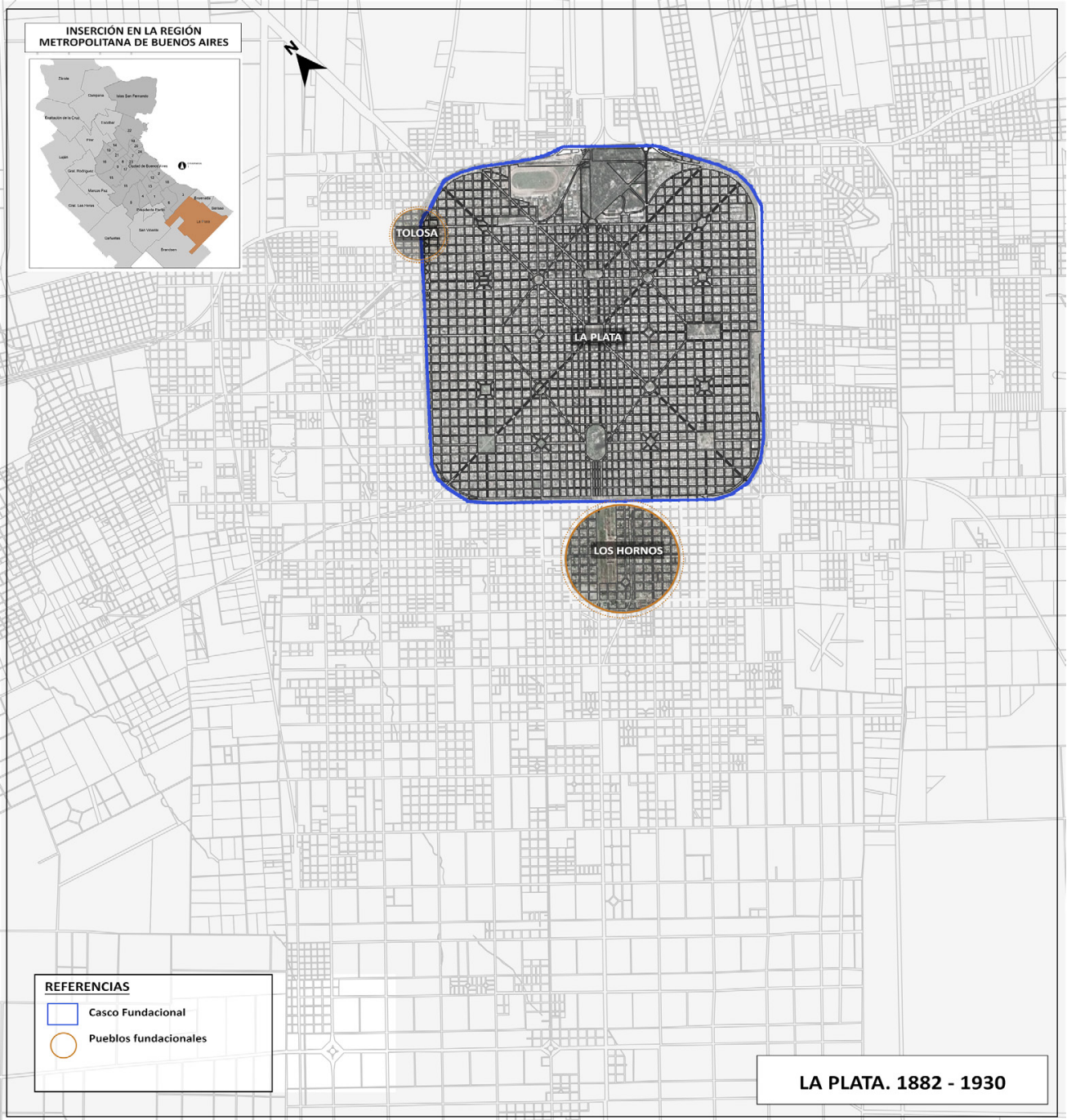

Fuente: Elaboración propia en base a datos catastrales de Agencia de Recaudación Provincia de Buenos Aires (ARBA), 2020. https:// carto.arba.gov.ar/cartoArba/

La importancia de la Avenida Circunvalación radica en ser el límite físico entre la ciudad real y la ciudad ideal hecho que se ve desvanecerse aún más en el periodo que va desde los años 1930 a 1975, durante los cambios producidos mediante la transformación del modelo económico agroexportador al de industrialización por sustitución de importaciones, ya que se verifica un mayor crecimiento en las localidades extra urbanas respecto del casco, profundizando las desigualdades de las delegaciones periféricas de La Plata (Figura 2). El auge del automóvil y el transporte público automotor, favoreció el crecimiento de la ciudad sobre las vías principales de conexión hacia el noroeste, en el eje que une La Plata y Buenos Aires, con una mayor presencia de sectores socioeconómicos medios y medios-altos (Curtit, 2003). Las transformaciones del modelo económico generaron migraciones desde sectores rurales hacia la ciudad, quienes por la escasez de recursos no pudieron resolver sus demandas habitacionales en el casco urbano. Esto generó un incremento y densificación de las periferias sureste y suroeste, con una mayor presencia de familias de bajos recursos, ayudadas por las políticas de vivienda impulsadas por el Estado y las ocupaciones de tierra (Frediani, 2010). 
Figura 2

La Plata, 1930-1970

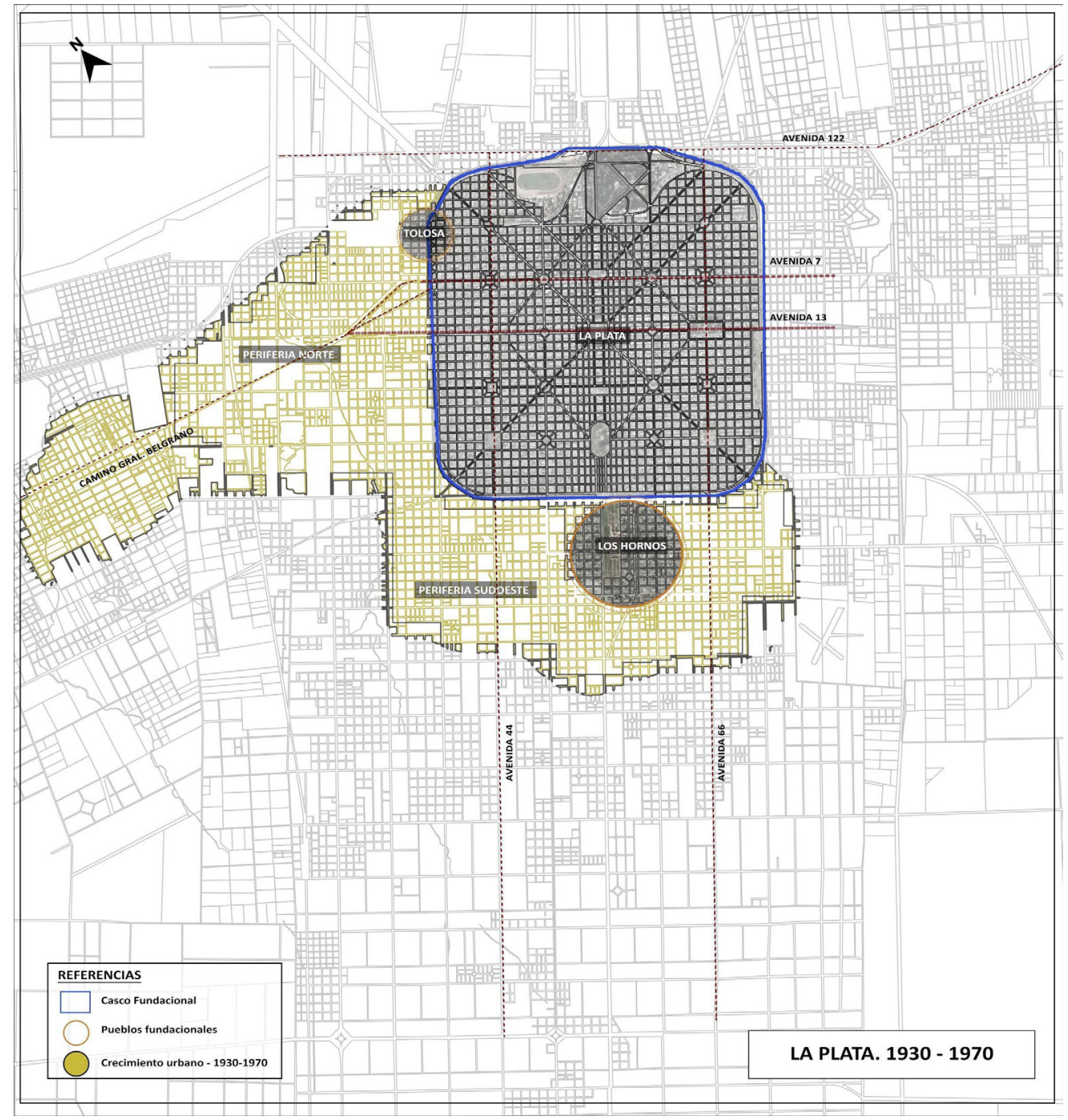

Fuente: Elaboración propia en base a datos catastrales de Agencia de Recaudación Provincia de Buenos Aires (ARBA), 2020. https:// carto.arba.gov.ar/cartoArba/

Las transformaciones que podemos identificar plasmadas bajo el modelo neoliberal, desde los años 1976 a 2003 (Figura 3), dejaron una fuerte participación estatal en favor de una desregulación del mercado y una privatización del sector público; iniciándose principalmente durante la dictadura militar de 1976-1983 y consolidándose en la década de 1990 con el gobierno del presidente Carlos Saúl Menem. En este periodo se acentuó la extensión de la marcha urbana con prolongaciones lineales a lo largo de las avenidas 7 y 122 (hacia sudeste), 44 y 66 (hacia el sudoeste), lo cual favoreció el establecimiento de los sectores populares dentro de esta región donde se registra un incremento de los asentamientos y el mayor crecimiento poblacional del Partido (Frediani, 2009). Asimismo, existe una consolidación socioeconómica del sector noroeste a partir la conurbación del eje noroeste sobre los ejes conformados por las avenidas 7 y 13 y el Camino General Belgrano, desarrollando crecientes barrios cerrados y clubes de campo. Esto genera la consolidación definitiva del eje La Plata-Buenos Aires y la configuración de una suburbanización de tipo lineal mediante un tejido continuo de uso mixto habitacional, comercial y de esparcimiento (Frediani, 2010). 
Figura 3

La Plata, 1970-2001

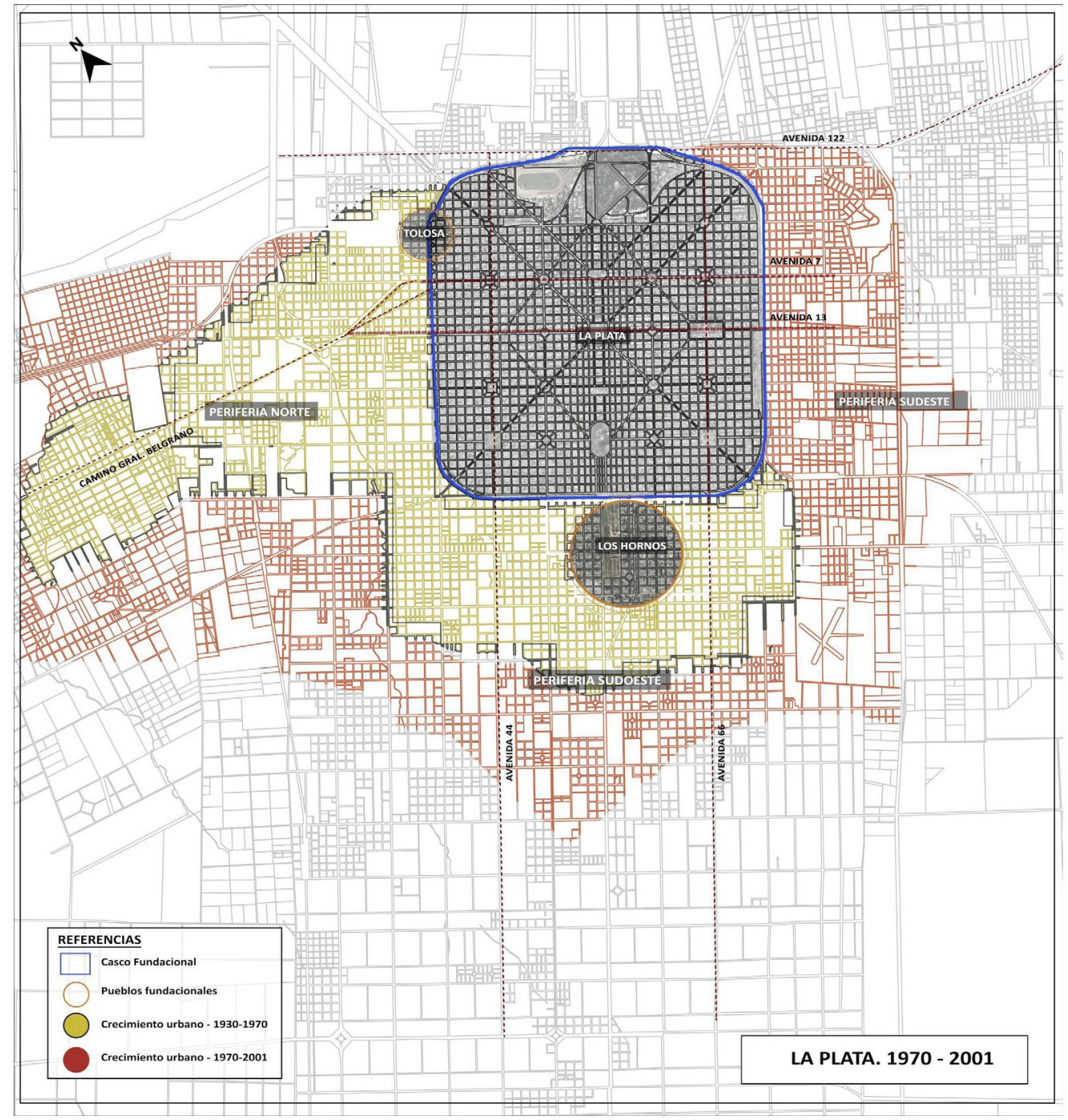

Fuente: Elaboración propia en base a datos catastrales de Agencia de Recaudación Provincia de Buenos Aires (ARBA), 2020. https:// carto.arba.gov.ar/cartoArba/

Luego del período de convertibilidad que generó la crisis socioeconómica del año 2001, la cuestión del desarrollo interno fue un eje fundamental para el país y la región (Beccaria \& Maurizio, 2012). A principio de este ciclo, la economía creció a un ritmo acelerado impulsado, principalmente, por la expansión del mercado interno y las exportaciones del agro (Dalle, 2012). El impulso de la industria de la construcción produce un crecimiento y densificación del casco fundacional, y un incremento del mercado inmobiliario, con escasa normativa que lo regule (Frediani, 2010). Esto genera una revalorización de las tierras del casco céntrico en detrimento de las del resto de la ciudad, donde la desvalorización aumenta cuanto más alejados se localizan los terrenos del centro urbano. Sin embargo, se encuentra en la periferia norte, Gonnet y City Bell, un cambio de dicha lógica, la cual, es necesaria comprenderla en clave histórica. Dichas delegaciones se encuentran a mayor distancia que las de la primera corona, pero sus valores son bastante más elevados, por lo cual, la distancia al centro urbano no es una variable lineal de valorización de suelo (Frediani, 2009). 


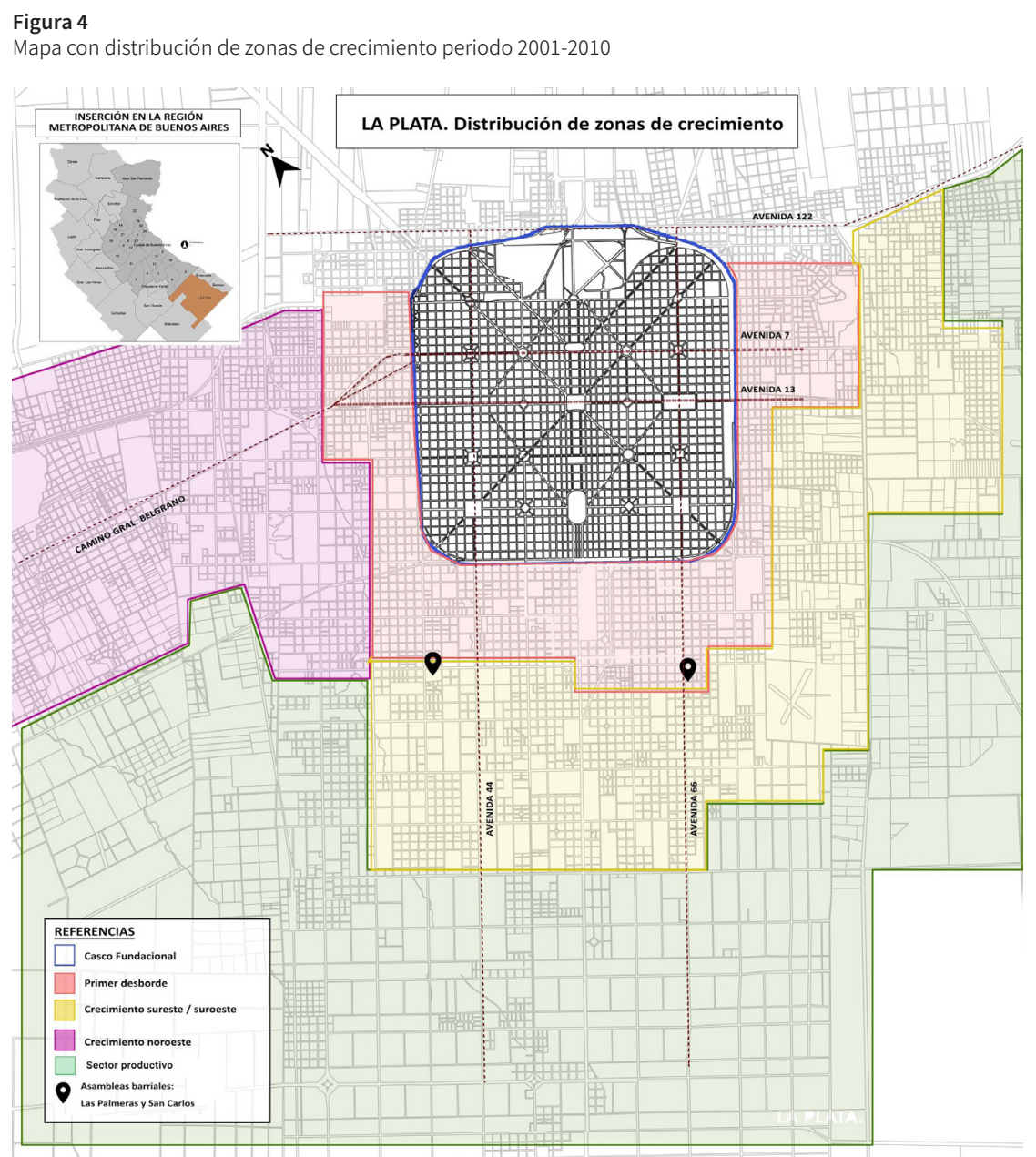

Fuente: Fotografía del autor, de original en el Archivo Gobernación Provincial de Tocopilla.

El contraste que observamos en el crecimiento urbano entre el casco fundacional y su periferia, se suma a la actualidad urbana donde se ha propiciado el auge de la privatización y la pérdida de los espacios públicos y como nos plantea Sznol, las ciudades "se están reinventando para dejar atrás el modelo modernizador de expansión de fronteras sociales y urbanas que representaba a la sociedad a partir de un imaginario de inclusión. La desaparición de ese horizonte de crecimiento tiene entre sus principales dimensiones, la crisis del espacio público" (2007, p. 30). La segregación social ha generado una fragmentación urbana, cuyas principales fuerzas son los procesos tecnológicos, económicos, sociales, culturales y políticos asociados a la globalización y al neoliberalismo, viéndose reflejado en el espacio público, el uso del mismo y la participación ciudadana en las problemáticas del hábitat (Burgess, 2009). Este proceso se ve reflejado en las periferias platenses, desabastecidas y con escasa infraestructura física y social, donde la lucha por y en el espacio público, las debemos abordar en el marco del derecho efectivo a la ciudad (Harvey, 2014).

\section{Estructura social y urbana del área de estudio}

Las tendencias asimétricas que observamos en el breve recorrido histórico de la ciudad, deben ser contrastadas con las condiciones socioeconómicas actuales a fin de comprender los procesos simbólicos y las disputas materiales que resultaron de la actividad asamblearia. Para esto, se utilizaron los datos del último Censo Nacional realizados en 2010, comparando las delegaciones de estudio con el resto del partido para dar cuenta de la situación de marginalidad socioespacial que atraviesan sectores sociales de ambas delegaciones (ver Tabla 1). 
Tabla 1

Datos socioeconómicos de La Plata.

\begin{tabular}{|c|c|c|c|c|}
\hline & Hogares con NBI & $\begin{array}{l}\text { Estudios en personas de } \\
25 \text { años o más }\end{array}$ & Nacionalidades & Condición laboral \\
\hline Casco fundacional & $3 \%$ & $\begin{array}{l}3,4 \% \text { sin instrucción o } \\
\text { primario incompleto } \\
50,4 \% \text { secundario } \\
\text { completo } \\
27,7 \% \text { universitario } \\
\text { completo }\end{array}$ & $\begin{array}{l}\text { 95,9\% Argentina } \\
\text { 2,2\% Países limítrofes y } \\
\text { Perú } \\
\text { 1,9\% Otros países }\end{array}$ & $\begin{array}{l}73,2 \% \text { Ocupado } \\
4,3 \% \text { Desocupado } \\
22,6 \% \text { Inactivo }\end{array}$ \\
\hline Primer desborde & $11 \%$ & $\begin{array}{l}9,3 \% \text { sin instrucción o } \\
\text { primario incompleto } \\
43,5 \% \text { secundario completo } \\
11,0 \% \text { universitario } \\
\text { completo }\end{array}$ & $\begin{array}{l}94,1 \% \text { Argentina } \\
4,4 \% \text { Países limítrofes y } \\
\text { Perú } \\
1,5 \% \text { Otros países }\end{array}$ & $\begin{array}{l}73,4 \% \text { Ocupado } \\
4,9 \% \text { Desocupado } \\
21,7 \% \text { Inactivo }\end{array}$ \\
\hline $\begin{array}{l}\text { Crecimiento sureste } \\
\text { suroeste }\end{array}$ & $38 \%$ & $\begin{array}{l}18,4 \% \text { sin instrucción o } \\
\text { primario incompleto } \\
29,9 \% \text { secundario completo } \\
3,0 \% \text { universitario completo }\end{array}$ & $\begin{array}{l}89,8 \% \text { Argentina } \\
9,6 \% \text { Países limítrofes y } \\
\text { Perú } \\
0,6 \% \text { Otros países }\end{array}$ & $\begin{array}{l}71,9 \% \text { Ocupado } \\
5,5 \% \text { Desocupado } \\
22,6 \% \text { Inactivo }\end{array}$ \\
\hline Crecimiento noroeste & $9 \%$ & $\begin{array}{l}6,9 \% \text { sin instrucción o } \\
\text { primario incompleto } \\
43,5 \% \text { secundario completo } \\
23,1 \% \text { universitario } \\
\text { completo }\end{array}$ & $\begin{array}{l}\text { 96,3\% Argentina } \\
\text { 2,2\% Países limítrofes y } \\
\text { Perú } \\
\text { 1,5\% Otros países }\end{array}$ & $\begin{array}{l}76,1 \% \text { Ocupado } \\
3,8 \% \text { Desocupado } \\
20,1 \% \text { Inactivo }\end{array}$ \\
\hline Sector productivo & $40 \%$ & $\begin{array}{l}21,0 \% \text { sin instrucción o } \\
\text { primario incompleto } \\
29,9 \% \text { secundario completo } \\
6,0 \% \text { universitario completo }\end{array}$ & $\begin{array}{l}\text { 87,9\% Argentina } \\
\text { 10,8\% Países limítrofes y } \\
\text { Perú } \\
\text { 1,4\% Otros países }\end{array}$ & $\begin{array}{l}75,6 \% \text { Ocupado } \\
4,0 \% \text { Desocupado } \\
20,4 \% \text { Inactivo }\end{array}$ \\
\hline
\end{tabular}

Fuente: Elaboración propia.

Los barrios de estudio se ubican en el eje de crecimiento de sureste-suroeste, donde se encuentran los porcentajes más elevados de población con necesidades básicas insatisfechas (NBI), y la disputa por el espacio urbano radica en cuestiones esenciales vinculadas al mejoramiento barrial como calles, agua potable, electricidad, entre otros. Los datos arrojados por el censo son georeferenciados en la Figura 4.

Los datos de la Tabla 1 arrojan información relevante sobre nuestros casos de estudio, para reconocer e identificar su conformación socioeconómica. Ambas delegaciones se ubican en el crecimiento sureste-suroeste (Figura 4), donde se encuentran los índices de NBI más altos (38\%) y junto a la condición laboral y educativa determinan la zona de mayor vulnerabilidad social y urbana del Partido de la ciudad de La Plata. Respecto al nivel de estudio, estamos en presencia de población sin instrucción o primario incompleto (18.4\%), pocos con secundario completo $(29.9 \%)$ y casi inexistente con título universitario (3\%). Esto da cuenta de que son sectores populares sin acceso a educación, donde tal como plantea Bourdieu (2001), el lugar que ocupan en la estructura social se traduce en el espacio urbano. Esto también se vincula con las nacionalidades, dado que es una de las zonas con mayor índice de inmigración de países limítrofes y Perú (9.6\%). Con respecto a la condición laboral, se puede ver que es una de las áreas con mayor desocupación (5.5\%) y con población inactiva (22.6\%) lo cual agrava su posibilidad de acceder a una vivienda de mejor calidad y servicios, además al ser parte del cordón florifrutihortícola, poseen empleos atravesados por la precarización social y laboral. En síntesis, la grave situación socioeconómica que atraviesan los hogares de los barrios seleccionados se traduce a nivel urbano en una segregación socioterritorial que determinan considerablemente sus posibilidades de acceso a un hábitat digno.

\section{Acciones colectivas en los barrios de estudio: San Carlos y Los Hornos ${ }^{2}$}

El desborde urbano hacia el sudoeste, ha generado un crecimiento consecuente con la cuadrícula del tejido

2 Para comprender la conformación política de La Plata, vale aclarar que la división territorial se conforma a partir de delegaciones (Figura 5), las cuales son instituciones administrativas, de menor escala que el Partido, dependientes de este, utilizadas como método de descentralización. Asimismo, la responsabilidad jurídica permanece al municipio delegante. 


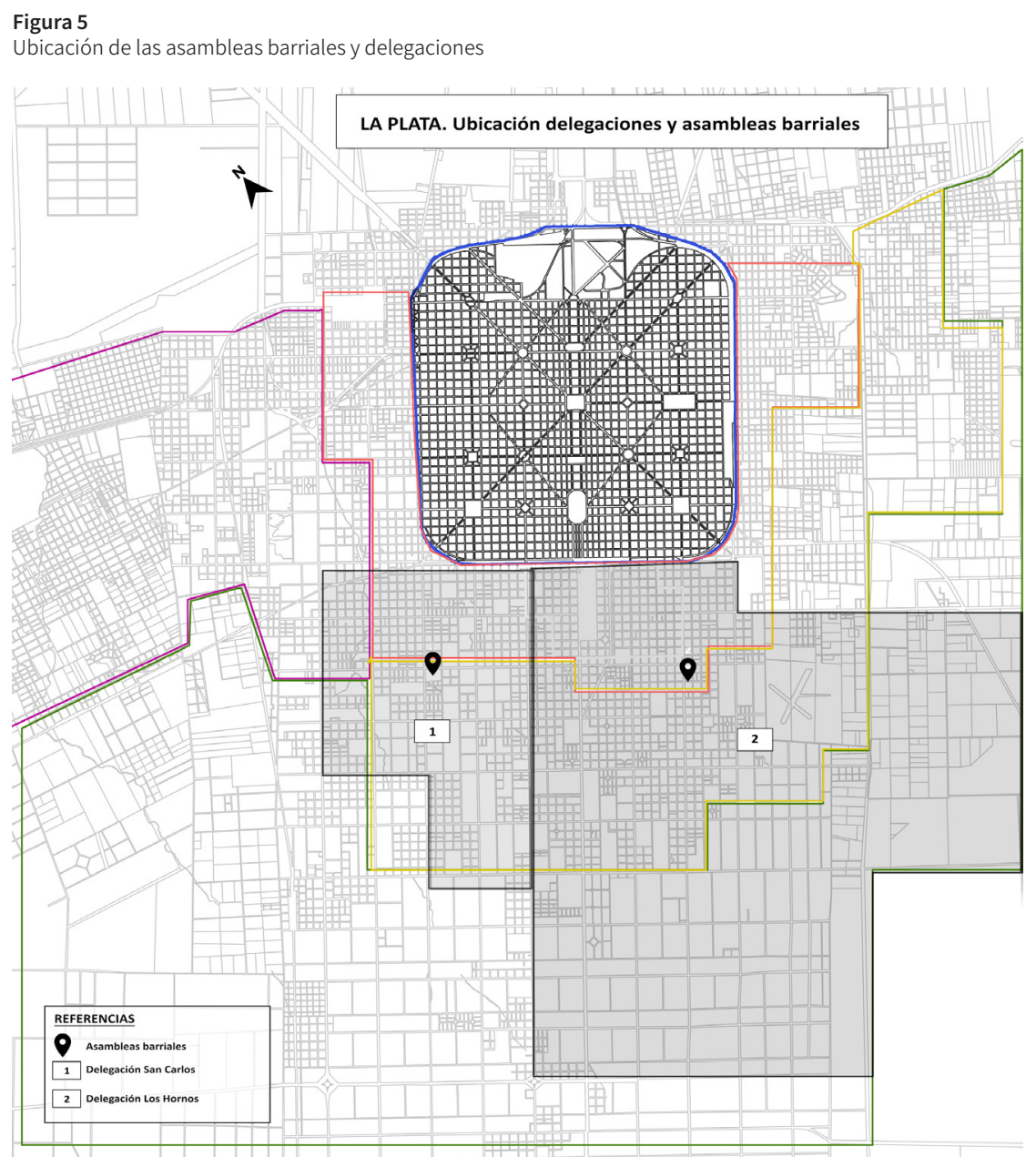

Fuente: Elaboración propia en base a datos catastrales de Agencia de Recaudación Provincia de Buenos Aires (ARBA), 2020. https://carto.arba.gov.ar/cartoArba/.

urbano en su inicio, la cual a medida que se aleja de estos puntos, comienza a perder las características físicas tradicionales de las avenidas cada seis cuadras y plazas en su intersección. Este proceso continuo y repetitivo, sumado a la falta de servicios públicos y equipamiento urbano, ha producido una pérdida de calidad en el hábitat urbano y un proceso segregador remitido a ciudadanos/as de clases bajas e inmigrantes. En el caso de Los Hornos, fue poblada previamente al casco fundacional, con la llegada de inmigrantes a la provincia y la creciente producción de ladrillos. En cambio, San Carlos ha sido producto del desborde fundacional, tal como se aprecian en la Figura 5.

Ambos barrios se encuentran ubicados próximos arroyos, lo que los convierte en zonas inundables y la situación habitacional se torna aún más crítica. Construidos en contextos disímiles, encuentran similitudes en términos de infraestructura. La mixtura entre calles asfaltadas y de tierra, nulas veredas y un escaso mobiliario urbano, donde el espacio público sólo puede ser utilizado para la movilidad desde el espacio privado al lugar de destino.

En este contexto, se dieron dos eventos disruptivos en el que las condiciones de identificación de los sujetos con el territorio se transformaron. La inundación del 2 de abril de 2013 y la baja del suministro eléctrico de junio de 2016 fueron disparadores para la participación vecinal en procesos asamblearios. En ambos casos, los/ as vecinos/as se encuentran organizados/as por fuera del ámbito doméstico, en búsqueda de una solución al hecho anómalo que estaban viviendo. De esta manera, el espacio público barrial fue el centro de la escena política, donde la plaza y la calle sirvieron para organizar 


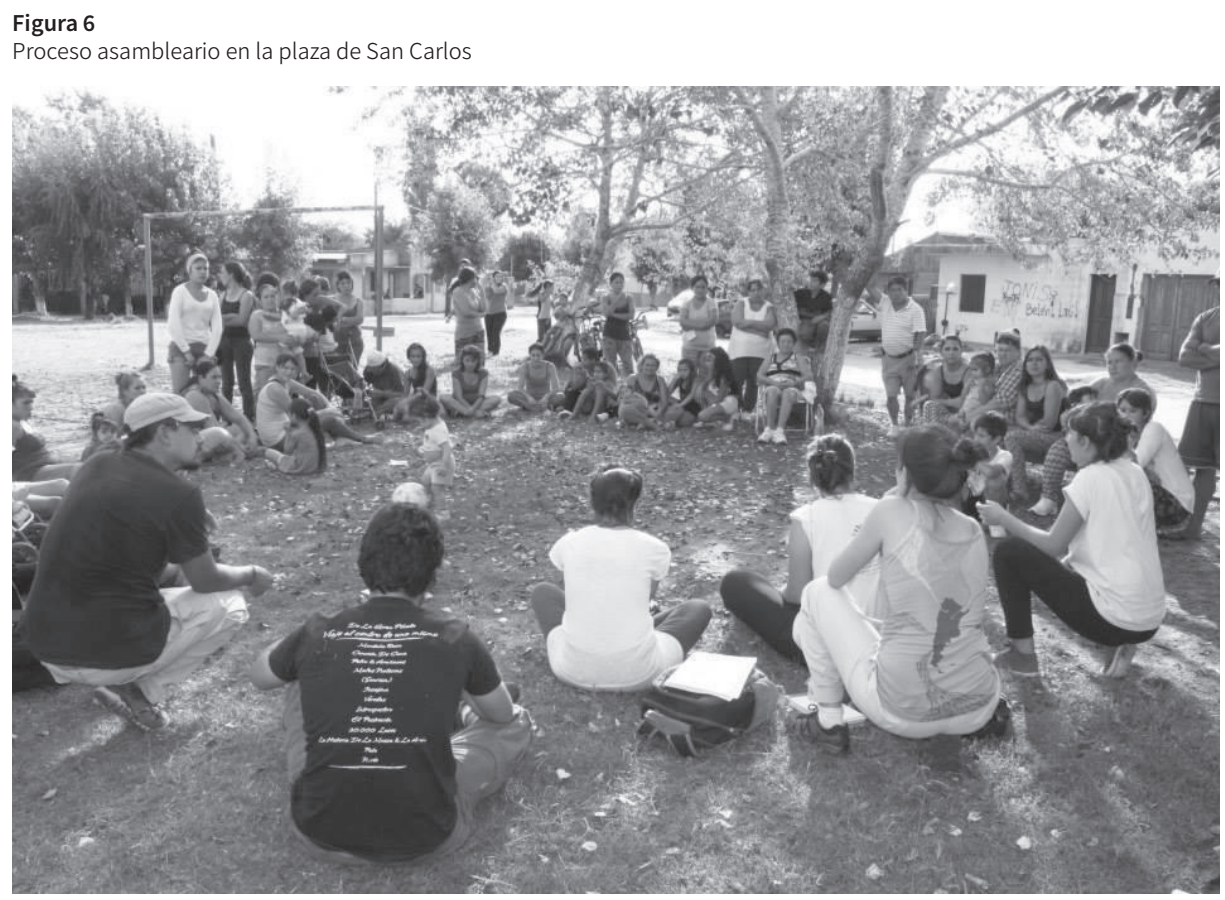

Fuente: organización ArqCom LP, Año 2014

las acciones que se debían llevar adelante ante las escasas respuestas que el Estado les brinda a las familias (Figura 6). Además de los/as vecinos/as, participaron activamente dos organizaciones sociales que iniciaron su primer contacto con el barrio luego de los hechos mencionados. Una era un partido político, la Unión del Pueblo (UP), mientras que la otra, Arquitectos de la Comunidad (ArqCom) conformada como organización técnico-política.

Fue así, como de la participación en el espacio barrial, se tomó la decisión de realizar cortes de calle en el centro de la ciudad trasladando la lucha al espacio territorial, construyendo en esta forma de proceder en el espacio urbano, el lugar donde se tejen lazos de solidaridad y pertenencia importantes, haciendo una revalorización propia (Torres, 2011). En ambos casos, la disputa social se dio a través de un conjunto de intereses colectivos que compitieron por la influencia sobre las políticas públicas, todos ellos dentro del marco de reglas del juego bien establecidas (Migdal, 2011), para revertir la situación barrial.

Durante las entrevistas realizadas, se encuentran analogías y contradicciones en las representaciones vinculadas a la problemática particular de cada barrio. La construcción discursiva relacionada a la participación activa de los/as vecinos/as del barrio y la dimensión material del espacio, le otorga nuevas formas a la dimensión simbólica, en la disputa urbana. Previo al análisis discursivo en torno a las asambleas, nos parece necesario remitirnos al medio material que dio lugar a los procesos organizativos. A continuación se presenta un cuadro comparativo (Tabla 2), con el fin de evidenciar condicionantes que dieron lugar a la participación de los/as afectados/as. Los datos recogidos son resultado de las entrevistas a vecinos, vecinas y nuestra participación en todo el proceso asambleario.

Los siguientes fragmentos fueron recuperados de las entrevistas realizadas a los/as referentes de los procesos organizativos una vez disuelta la asamblea. A partir de la voz de los/as vecinos/as, se indaga en qué tipo de vínculos se construyeron entre el espacio público y el proceso asambleario. A su vez, se exploró qué tipo de relaciones dejó dicha actividad en cada barrio y cuáles fueron los significados que les atribuyen a las mejoras barriales. A continuación se presentan cuatro ejes de análisis, en donde se ven diferencias y similitudes entre ambos procesos asamblearios.

\section{Imaginarios de la asamblea}

La asamblea fue el método utilizado en ambos casos como forma de construcción política y social, a la vez que 
Tabla 2

Cuadro comparativo de las acciones colectivas.

\begin{tabular}{|c|c|c|}
\hline & Los Hornos / Las Palmeras & San Carlos \\
\hline Causa que motivó la participación vecinal & Baja del suministro eléctrico & Inundación el 2 de abril de 2013 \\
\hline Lugar donde se realizó la asamblea & Calle - Esq. 144 y 71,145 y 71 & Plaza barrial - 145 y 50 \\
\hline Participantes de la asamblea & Gran parte eran vecinas y organizaciones sociales & $\begin{array}{l}\text { En su mayoría eran vecinas y organizaciones } \\
\text { sociales }\end{array}$ \\
\hline Lugar de procedencia & Paraguay - Argentina & Paraguay - Bolivia - Argentina \\
\hline Tiempo que duró la asamblea & 1 año & 4 años \\
\hline Infraestructura / Servicios & $\begin{array}{l}\text { Agua de manguera - Electricidad - Gas envasado } \\
\text { - Pozo absorbente - Alumbrado público sobre } \\
\text { avenida principal }\end{array}$ & $\begin{array}{l}\text { Agua de red - Electricidad - Gas envasado - Pozo } \\
\text { absorbente - Alumbrado público - Recolección } \\
\text { de basura }\end{array}$ \\
\hline $\begin{array}{l}\text { Mejoras y actividades de la cual los procesos } \\
\text { asambleario fueron parte }\end{array}$ & $\begin{array}{l}\text { Suministro del alumbrado público, relevamiento } \\
\text { y mapeo del barrio, proyectos para la mejora } \\
\text { parcial de viviendas, talleres de electricidad y } \\
\text { construcción de pilares, mejoramiento de calles y } \\
\text { apertura de zanjas. }\end{array}$ & $\begin{array}{l}\text { Materiales y proyectos para la mejora parcial de } \\
\text { las viviendas, asfalto en calles, puentes vehicular } \\
\text { y peatonal, festejos del día del niño y navidad, } \\
\text { talleres de mujeres }\end{array}$ \\
\hline Espacios verdes & Club Alumni (148 y 72 ) & Plaza (50 y 145$)$ \\
\hline
\end{tabular}

Fuente: Elaboración propia (2020).

medio para revertir la situación que se estaba viviendo. A continuación se presentan los recuerdos sobre las asambleas, tratando de visualizar el vínculo que se tuvo con el barrio y el espacio público donde se desarrollaron:

El tema de la asamblea por ejemplo, lo que a mí más me daba confianza era que conocía a la gente, conocía quien era fulano y charlabas, y sabías que había gente que la estaba pasando mal, que no eras la única. [...] Otra cosa fue que logramos muchas cosas con los vecinos, no es que fue una asamblea que quedó en la nada, creo que todos los vecinos tienen recuerdos importantes de lo que pasó y se pudo hacer en ese momento. Creo que si algo pasara ahora, los vecinos no dudarían en movilizarse y hacer cosas. (María, 30 años, cuidadora, referente de la asamblea de Las Palmeras) ${ }^{3}$

Era como que algo se estaba construyendo para el barrio y como que a nosotros nos alentaba a salir, no sé si de una burbuja, pero de conocer otra gente, tener otros pensamientos, porque capaz nosotros estábamos encerrados en nuestros propios pensamientos y no vamos más allá. Existía la posibilidad de hacer algo mejor y ves que lo rutinario de todos los días se puede transformar en otra cosa. (Rocío, 45 años, cocinera, referente de la asamblea de San Carlos)

Lo único que tendría que decir, gracias a la asamblea. Si no hubieran estado ustedes, nosotros no lo hubiéramos hecho, nos dieron el empujoncito. Estaríamos llorando en vez de luchar. Los que estuvimos en la asamblea, aprendimos a luchar, a salir adelante, a progresar, a querer vivir mejor, más allá de si lo podemos conseguir o no. [...]. (Graciela, 57 años, manzanera, referente de la asamblea de San Carlos)

En ambos barrios, la situación detonante fue desde lo individual hacia lo colectivo. La problemática se sufrió, en primera instancia, dentro del espacio doméstico y luego se colectivizo en el barrio. Esto determinó la forma de actuar y la construcción simbólica que se dio alrededor de la participación en las asambleas. Como respuesta a la situación disruptiva, la asamblea se convirtió en un eje de transformación tanto material como simbólica del habitar y transitar el barrio (Segura, 2015). En los relatos y a partir de la observación participante, encontramos similitudes en cómo la asamblea se convirtió en el motor de las mejoras físicas del barrio (Figura 8) y, a su vez, en un dinamizador de las relaciones entre los/as vecinos/ as. Así es que en y a través del espacio, los/as vecinos/ as rompen el aislamiento y el "ninguneo" al que los/ as reduce su situación de exclusión, conformando un "nosotros/as" que les otorga existencia social (Sznol, 2007) y un sentido de pertenencia al propio barrio.

A su vez, se observa la huella que dejó la asamblea en quienes participaban. Las mejoras materiales a escala barrial, los nuevos lazos sociales que se establecieron

3 Los nombres han sido modificados para garantizar el anonimato de los y las entrevistadas. 
y el reconocimiento del sujeto en una red que supera el ámbito doméstico, pone en valor la importancia de las acciones colectivas en barrios periféricos, a la vez que, como comentaban las asambleístas, generan futuros de posibilidad diferentes a los establecidos. De esta manera, la acción colectiva constituye una dimensión activa que puede transformar los vínculos entre vecinos/ as a partir del conocimiento y reconocimiento con otros individuos y llevar a nuevos pactos de interacción social (Galtung, 2016).

\section{La participación y el vínculo entre los/as vecino/as y las organizaciones}

Dentro de los imaginarios creados en las asambleas fue la participación activa, para revertir la situación disruptiva, una constante en ambos barrios. El proceso asambleario como hecho movilizador y visualizador de las problemáticas individuales y cotidianas, tácitas entre los vecinos y vecinas, generó diversas territorialidades en el espacio público. A continuación se refleja lo mencionado:

Al principio no querían participar pero cuando vieron que llegaban los materiales, querían venir y participar, ellos vieron que todo se hizo como dijimos que iba a pasar. Por eso la gente está acostumbrada a que los aprieten, que te digan tenés que venir a la asamblea para que te den los materiales, y por los materiales iría a la asamblea, pero no por la asamblea. (Graciela, 57 años, manzanera, referente de la asamblea de San Carlos)

Hay mucha posibilidad, si los vecinos somos unidos, podemos hacer muchas cosas acá en el barrio y más con apoyo de ustedes pero no somos unidos. (Clara, 49 años, empleada doméstica, vecina de San Carlos)

En ambos casos, la participación de vecinos/as del barrio se ha visto condicionada por la irrupción y participación de agentes externos al ámbito barrial-las organizacionesquienes son caracterizadas como dinamizadoras de las acciones colectivas. Con la disipación de la misma, se otorgan ciertas significaciones sobre los vínculos generados entre ambos.
Después quedaban muchas posibilidades, me acuerdo que nos dijeron que se trazaría un mapa del barrio, que ustedes se encargaron de hacer eso, entre los vecinos, que trabajamos. Después de eso, qué se podía hacer, si hacer pilares entre los vecinos o comprarlos (...) se charlaba asílas posibilidades de qué vecinos sabían hacer el trabajo y quienes podían ayudar y hacer, era bastante interesante. (María, 30 años, cuidadora, referente de la asamblea de Las Palmeras)

Había gente, los estudiantes y la gente de techo, pero tampoco nos funcionó tanto, algunas cosas hicieron pero no se pudo hacer tanto, porque acá los vecinos no. Está el colo y eso, nos suspendieron muchas cosas. (Luis, 54 años, albañil, vecino de Las Palmeras)

Vinieron ustedes, después conseguimos las cosas materiales, gracias a ustedes. Sin ustedes nosotros no conseguíamos nada. [...] Gracias a ustedes, porque ustedes se movieron. Si era por los vecinos, íbamos a estar sin puentes, sin calle, sin casa. Gracias a ustedes. (Clara, 49 años, empleada doméstica, vecina de San Carlos)

Todos/as los/as entrevistados/as, visualizaron a los distintos actores que participaron de la asamblea. En ambos casos la identificación y empatía otorgada a los actores externos del barrio, no se condicen con los vínculos estrechados entre vecinos/as durante el proceso asambleario, quienes atraviesan las mismas territorialidades y problemáticas cotidianas (Tabla 2). Este factor, repercute significativamente en el momento de la disolución de las asambleas, ya que los vínculos establecidos durante el proceso asambleario son menos al interior del barrio (con vecinos/as), que hacia el exterior (con organizaciones). Este proceso de alteridad genera una negación hacia el espacio barrial que se habita.

\section{La relación de la asamblea con el Estado y el espacio público diferenciado}

En los presentes casos de estudio, al tener distintas escalas de damnificación, las relaciones que se establecieron con el Estado tienen ciertas diferencias. En el caso de la inundación, ya desde los primeros contactos entre el Estado con los/as vecinos/as, se observaron problemas. 
En los siguientes relatos se verifica esta situación, dejando en evidencia la escasa respuesta por parte del Estado propiciando las diferencias hacia el interior del barrio:

Después daban bastantes materiales, de aquél lado que no se inundaron le dieron un montón de materiales y los vendieron. Verdaderamente no hubo un control, está bien que den pero controla que se hizo, que se va a hacer con lo que te están dando. (Mariano, 42 años, herrero, vecino de San Carlos)

Ver que el gobierno hizo mal las cosas, llevó cosas donde no se había inundado y la gente que se había inundado no recibió nada. Habían traído colchones y los dejaron en la placita pero ahí nadie se había inundado, después trajeron agua a 49 y 146 y me pelee con los vecinos que viven en la placita porque venían a buscar y ellos no se habían inundado. (Graciela, 57 años, manzanera, referente de la asamblea San Carlos)

Se puede observar como el Estado reforzó la problemática de la inundación propiciando la disputa al interior del barrio entre los/as vecinos/as. Si bien, algunos/as se habían inundado y otros/as no, el Estado no intervino entre quienes repartían los bienes materiales y las necesidades estructurales del barrio se vieron reflejadas. En este sentido, utilizó no sólo su fuerza física sino también su legítima fuerza simbólica ya que tuvo el poder de nombrar quien se había inundado, y que tipo de necesidades tenía (Brubaker y Cooper, 2001). Si bien esto fue mal visto en las/os entrevistadas/os, la fuerza simbólica constituida hizo que no se ponga en duda la legitimidad para construir dichas identificaciones.

Por otro lado, la dinámica asamblearia al interior de ambos barrios impulsó la idea de visibilizar la protesta en el casco céntrico de La Plata, irrumpiendo en el cotidiano y mostrando al resto de la sociedad las demandas pendientes de materiales e infraestructura. Así fue como se construyeron dos representaciones del espacio público, el del barrio como lugar de organización y el del casco céntrico como territorio de disputa.

Nosotros fuimos a hacer el corte el lunes, y el miércoles vino Telefe, el Trece todo eso, y el finde lo sacaron al aire, y un domingo cayó Edelap, a las dos de la tarde, empezó a poner poste por postey tiraron el cable, ¿Era tan difícil? Tan difícil de hacer no era. [...] Hubo un montón de excusas. Pasaron dos semanas más o menos. (María, 30 años, cuidadora, referente de la asamblea de Las Palmeras)

En ambos casos, las estrategias de disputa hacia el Estado fueron las mismas. El corte de calle en la zona céntrica de la ciudad, sirvió de dinamizador para revertir las situaciones puntuales que estaban atravesando las familias. Así es como vemos que cada miembro de la sociedad conoce mucho acerca del Estado y tal conocimiento no es incidental para la operación en la sociedad, sino que está involucrado en ella (Giddens, 1982). La utilización del espacio público, como espacio de disputa, fue apropiado por el Estado para construir límites a la lucha social, asegurándose de utilizar la fuerza física en cualquier exceso a dichos límites.

\section{Asamblea, espacio barrial e inseguridad}

En las distintas entrevistas, se encuentra una constante en torno a la relación entre el espacio público y la inseguridad. La visión de todos/as los/as entrevistados/as, hacia lo que sucede por fuera del espacio doméstico, denota una situación de extrañeza hacia el exterior. La construcción simbólica, que se reafirma a sí misma y a partir de hechos puntuales, genera la producción de un espacio inseguro. De esta manera, los miedos se perpetúan y se refuerzan cada vez más a sí mismos de tal manera que adquieren impulso propio (Bauman, 2006). Esto se ve reflejado en los siguientes fragmentos:

Que no haya movimiento es lo peor, no importa si está iluminado o no está iluminado. Casi es lo mismo, no evita nada si no hay seguridad acá. [...] Acá a la noche es zona liberada totalmente, no pasa ningún patrullero, la inseguridad mata acá. Pero los de acá no hacen nada, los de acá los conocemos, son gente de afuera, es un tema. (Fernanda, 25 años, acompañante, vecina de Las Palmeras).

Cuando voy a cierta hora, a la noche, como hombre no me preocuparía tanto por mí, pero si pienso que pasa -pareja- o alguna vecina chiquita que está medio oscuro o falta un foco o escucho el ruido de las motos, 
pasan y estás pensando que es lo que puede llegar a pasar. (Mariano, 42 años, herrero, vecino de San Carlos).

Me pasa eso, creo que es la situación constante (de inseguridad). A mí me da lo mismo salir acá de mi casa que salir allá en el centro. (María, 30 años, cuidadora, referente de la asamblea de Las Palmeras).

Se puede observar cómo en cada situación, la mirada hacia el exterior es la misma. El miedo refuerza la idea de la propiedad privada como refugio y genera la percepción de la inseguridad y el abandono del espacio público, en su dimensión física, simbólica y social, funcionando como un proceso circular y acumulativo (Segovia y Dascal, 2000). Para comprender mejor el proceso simbólico que se lleva adelanta, Virgina Vargas (2009) nos propone colocar el temor como categoría analítica, y la subjetividad como dato fundamental en el proceso de apropiación de los derechos del ciudadano. En este sentido, la relación del espacio público barrial y la inseguridad, es retomada consecutivamente por las vecinas o el uso que ellas tienen del mismo, otorgándole percepciones similares y ciertos sentidos más allá de las condiciones materiales del territorio transitado.

\section{Conclusiones}

Las acciones colectivas registradas en los casos de estudio permitieron identificar usos, apropiaciones y representaciones diversas sobre el espacio urbano por parte de los/as vecinos/ as, donde por medio de los significados establecidos en los procesos asamblearios se pudo apreciar cómo los hechos disruptivos transformaron la cotidianeidad del espacio barrial. El análisis de las entrevistas, dio cuenta que existen significados relacionados a la acción colectiva, que entran en contradicción y ponen en evidencia diversas miradas al interior de la misma. Podemos dar cuenta que en ambos casos de estudio, tanto la inundación como la caída del suministro eléctrico, interfirieron con la vida cotidiana obligando a las familias a salir del espacio doméstico. Ante este panorama, las acciones colectivas fueron las canalizadoras de las demandas para revertir la situación. Por medio del trabajo de campo, se observa que la participación de cada vecino/a está condicionada por dos aspectos interrelacionados: el rol de la experiencia y la construcción de territorialidades.
Por un lado, respecto al rol de la experiencia, se puede afirmar que en ambos barrios quienes se posicionan como referentes/ as habían tenido participación anterior en otros procesos colectivos -comedores, partidos políticos, organizaciones sociales, ONG- tensionando la acción colectiva por las diversas miradas que se construyeron previamente. A su vez, las mismas se han visto condicionadas por los imaginarios y significados construidos en torno a la participación política en diferentes instancias barriales previas. De esta manera, mientras algunos/as vecinos/as solo visualizan la mejora física del barrio, como hechos concretos asimilados a la participación del Estado o de organizaciones sociales, otros/as han construido ciertos significados en torno a la organización barrial como hecho político y dinamizador. $\mathrm{Si}$ bien las acciones colectivas se han disuelto al momento de realizar las entrevistas, a través de las mismas se puede dar cuenta que los imaginarios construidos en las asambleas analizadas, construyen una determinada experiencia que proyecta sobrelos/las vecinos/as involucrados/as la posibilidad de futuras acciones colectivas transformando las relaciones y prácticas socioespaciales en el habitar cotidiano.

Por otro lado, en referencia a la construcción de territorialidades se observa la multiplicidad de escalas que se construyeron a través de la intervención de las acciones colectivas analizadas. En primera instancia, en cuanto al espacio urbano de la ciudad de La Plata se identifican dos espacios públicos diferenciados. Uno en el casco fundacional, donde la interrupción del tránsito generó la visualización de una problemática de un sector de la sociedad, que por condiciones territoriales es invisibilizada, y un segundo lugar donde las acciones colectivas se fortalecieron a partir de una problemática colectiva del hábitat. Dichos procesos dejan ver las distintas estrategias de participación construidas en las asambleas, las cuales se entrelazan en el espacio público, diferenciando el de las periferias con el del centro urbano. De esta manera, la intervención por parte de las acciones colectivas en el casco fundacional genera una ruptura con las interacciones instrumentales entre el centro y la periferia, generando imaginarios y territorialidades diversas.

En segunda instancia, se observa que el espacio barrial se ha convertido en el espacio cotidiano, de encuentro social 
y de interacción entre los distintos actores. En esta escala, la acción colectiva fue el medio para movilizar al barrio y la herramienta fundamental para emplear nuevas prácticas e interacciones socioespaciales, creando nuevas percepciones del espacio cotidiano, impactando sobre los imaginarios y las experiencias, determinando cierto grado de cohesión social. A su vez, la observación participante y las entrevistas realizadas dejan entrever que la territorialidad construida por la acción colectiva, se ve confrontada por otros actores que participan del barrio con diversos intereses. Las mismas condicionan no sólo la participación en estos procesos, sino las dinámicas establecidas en las acciones colectivas.

Por otro lado, un hallazgo relevante del trabajo de campo en cuanto al espacio público barrial y presente en todas las dimensiones de análisis, es que fueron las mujeres quienes construyeron la asamblea del barrio, le dieron forma y participaron activamente. Lejos de asentarse dentro de la propiedad privada, salieron al espacio público a emprender una disputa que, sin su presencia, el mejoramiento del barrio nunca hubiese llegado. Si bien se expresó la desconfianza que se vive en el espacio público por parte de las mujeres, la dinámica de la asamblea generó un lugar de intercambio y confianza dentro del barrio, que en algunos casos fue más seguro que el propio espacio doméstico.

Finalmente, se quiere destacar que si bien ambos procesos presentan características similares en torno a la construcción de significados sobre el espacio público urbano y la acción colectiva, tuvieron desarrollos disímiles. Sin embargo, los relatos que surgieron del trabajo de campo demuestran reflexiones compartidas respecto a la necesidad de gestionar políticas urbanas que garanticen condiciones de habitabilidad dignas en los barrios más postergados de la ciudad. Esto nos hace reflexionar en cómo las desigualdades estructurales, sin desmerecer las diferencias circunstanciales, condicionan las prácticas socioespaciales de las acciones colectivas.

\section{Referencias bibliográficas}

Bauman, Z. (2006). Vida Líquida. Buenos Aires: PAIDOS.

Beccaria, L., \& Maurizio, R. (2012). Reversión y continuidades bajo dos regímenes macroeconómicos diferentes. Mercado de trabajo e ingresos en Argentina 1990-2010. Desarrollo Económico: Revista de Ciencias Sociales, 205-228.
Borja, J. (2014). Revolución urbana y derechos ciudadanos. Barcelona: Alianza Editorial.

Bourdieu, P. (2001). Efectos de lugar. En P. Bourdieu (Dir.), La miseria del mundo (pp. 249-262). México: Fondo de Cultura Económica.

Boy, M. (2018). El otro espacio público en los estudios urbanos de la Argentina actual: el género y las sexualidades también construyen ciudad.Quid 16 (9), 153-167. http://publicaciones. sociales.uba.ar/index.php/quid16/article/view/2893

Brubaker, R. y Cooper, F. (2001). Más allá de identidad. Apuntes de Investigación del CECYP, 5(7), 30-67.

Burgess, R. (2009). Violencia y la ciudad fragmentada. En Ana Falú (ed.), Mujeres en la ciudad. De violencias y derechos (pp. 99-126). Santiago de Chile: Ediciones SUR, Red mujer y Hábitat de América Latina.

Bustos Cara, R. (2005). La cultura en cuestión: estudios interdisciplinarios del sudoeste bonaerense. Buenos Aires: Historia Cultural.

Carrión M., F. (2016). El espacio público es una relación, no un espacio. En P. Ramírez Kuri (Ed.), La reinvención del espacio público en la ciudad fragmentada (pp. 13-50). México D.F.: Universidad Nacional Autónoma de México (UNAM).

Chapman, T. (2006). Public Space. Encyclopedia of human geography.

Curtit, G. (2003). Ciudad, gestión local y nuevos desafíos ambientales. Reflexiones a las políticas neoliberales y sus efectos sobre nuestros territorios. Buenos Aires.

Dalle, P. (2012). Cambios recientes en la estratificación social en Argentina (2003-2011). Inflexiones y dinámicas emergentes de movilidad social. Argumentos. Revista de crítica social, (14), 77-114. https://publicaciones.sociales. uba.ar/index.php/argumentos/article/view/893

Delgado, M. (2011). El espacio público como ideología. Madrid: Los libros de la Catarata. 
Duhau, E. (2009). Vida y muerte del espacio público. En M. Rodríguez y J. Roze (Eds.), Ciudades Latinoamericanas IV: Políticas, acciones, memoria y reconfiguración del espacio urbano (pp. 213-238). México: Universidad Autónoma de Guerrero - ALAS.

Duhau, E. (2013). La división social del espacio metropolitano. Una propuesta de análisis. Nueva Sociedad, (243). https://www.nuso.org/articulo/la-division-social-delespacio-metropolitano-una-propuesta-de-analisis/

Eilbaum, L. y Villalta, C. (2002). Zonas diferenciales en el espacio público: clasificaciones, distinciones y jerarquías. En Filc, J. (comp.), Territorios Itinerarios Fronteras (19902000), (pp.67-80). La Plata: UNGS - Ediciones al Margen.

Fenster, T. (2010). El derecho a la ciudad y la vida cotidiana basada en el género. Santiago: HIC.

Foucault, M. (1992). Vigilar y castigar. Madrid: Siglo XXI.

Foucault, M. (2009). La voluntad de saber. Madrid, Siglo XXI.

Frediani, J. C. (2009). Las nuevas periferias en el proceso de expansión urbana. El caso del partido de La Plata.

Geograficando: Revista de Estudios Geográficos 5(5). https:// www.geograficando.fahce.unlp.edu.ar/article/view/ GEOv05n05a05/pdf_52

Frediani, J. C. (2010). Lógicas y tendencias de la expansión residencial en áreas periurbanas. El Partido de La Plata, Buenos Aires, Argentina, entre 1990 y 2010 (Tesis). Doctorado en Geografía, Facultad de Humanidades y Ciencias de la Educación, Universidad Nacional de La Plata.http://www.memoria.fahce.unlp.edu.ar/tesis/ te.355/te.355.pdf

Galtung, J. (2016). La violencia: cultural, estructural y directa. Cuadernos de estrategia,(183), 147-168. https://dialnet. unirioja.es/servlet/articulo? codigo $=5832797$

Garnier, A. (1992). El cuadrado roto. Sueños y realidades de La Plata. La Plata: LINTA, CIC y Municipalidad de La Plata.

Giddens, A. (1982). Profiles and critiques in social theory. Los Ángeles:University of California Press.
Gregory, D. (1984). Ideología, Ciencia y Geografía Humana. Barcelona: Oikos-Tau.

Harvey, D. (1989). The urban experience. New York: John Hopkins.

Harvey, D. (2004). El nuevo imperialismo. Madrid: Akal.

Harvey, D. (2008). El derecho a la ciudad. New Left Review, 53(4), 23-39.

Harvey, D. (2014). Ciudades rebeldes. Del derecho de la ciudad a la revolución urbana. Madrid: Akal.

Instituto Nacional de Estadística y Censos [INDEC]. (2010). Censo Nacional de Población, Hogares y Viviendas 2010. Buenos Aires: INDEC.

Jacobs, J. (2011). Muerte y vida de las grandes ciudades. Madrid: Capitan Swing.

Kowarick, L. (1996). Expoliación urbana, luchas sociales y ciudadanía: retazos de nuestra historia reciente. Revista Estudios Sociológicos, 14(42), 729-743. https://dialnet. unirioja.es/servlet/articulo? codigo $=6163974$

Lefebvre, H. (1976). La producción del espacio. Espacio y Política, el derecho a la ciudad II. Barcelona: Península.

Marradi, A., Archenti, N. y Piovani, J. I. (2010). Metodología de las ciencias sociales. Buenos Aires, Argentina: Cengage Learning.

Martí Costa, M. y Bonet Martí, J. (2008). Los movimientos urbanos: de la identidad a la glocalidad. Scripta Nova, 12(270), 11389788. http://www.ub.edu/geocrit/sn/ sn-270/sn-270-121.htm

Melucci, A. (1999). Acción colectiva, vida cotidiana y democracia. México, D.F.: El Colegio de México. https:// doi.org/10.2307/j.ctvhn0c2h

Migdal, J. (2011), Estados Débiles, Estado Fuertes. México: Fondo de Cultura Económica.

Morosi, P., Romanazzi P. (2013). Genealogía de una tragedia. Inundación de La Plata, 2 de Abril de 2013. Buenos Aires: Marea. 
Oslender, U. (2002). Espacio, lugar y movimientos sociales: hacia una "espacialidad de resistencia". Barcelona: Scripta Nova.

Rainero, L. (2014). Espacios públicos. Convivencia y seguridad ciudadana. ¿Dónde están seguras las mujeres?. Vivienda y Ciudad, (1), 88-98. https://revistas.psi.unc.edu.ar/ index.php/ReViyCi/article/view/9543

Ravella, O. y Giacobbe, N. (2005). Tendencias y rupturas en la expansión urbana: relaciones entre movilidad y los procesos de globalización. Estudios del Hábitat, 2(8), 19-34.

Rodríguez Vignoli, J. (2008). Movilidad cotidiana, desigualdad social y segregación residencial en cuatro metrópolis de América Latina. EURE (Santiago),103), 49-71. http:// dx.doi.org/10.4067/S0250-71612008000300003

Segovia, O. y Dascal, G. (2000). Espacio público, participación y ciudadanía. Santiago de Chile: Ediciones SUR.

Segura, R. (2009). Paisajes del miedo en la ciudad. Miedo y ciudadanía en el espacio urbano de la ciudad de La Plata. Cuaderno Urbano, 8(8), 59-76.

Segura, R. (2011). La trama relacional de la periferia urbana. La figuración "establecidos y outsiders" revisitada. $V I$ Jornadas de Sociología de la UNLP, 9 y 10 de diciembre de 2010, La Plata, Argentina. En Memoria Académica. http://www.memoria.fahce.unlp.edu.ar/trab_eventos/ ev.5361/ev.5361.pdf

Segura, R. (2012). Elementos para una crítica de la noción de segregación residencial socio-económica: desigualdades, desplazamientos e interacciones en la periferia de La Plata. Quid, 16(2, 106-132. https://publicaciones. sociales.uba.ar/index.php/quid16/article/view/1118

Segura, R. (2013). Los sentidos del lugar. Temporalidades, relaciones sociales y memorias en un barrio segregado de La Plata (Argentina). Sociedade e cultura, 16(1), 59-68.

Segura, R. (2015). Vivir afuera. Antropología de la experiencia urbana. Buenos Aires: UNSAM.
Soja, E. W. (1985). The Spatiality of Social Life: Towards a Transformative Retheorisation. En Derek Gregory y John Urry (Eds.), Social relations and spatial structures (pp. 90-127). London: Palgrave. https://doi.org/10.1007/9781-349-27935-7

Soldano, D. (2008). Vivir en territorios desmembrados. Un estudio sobre la fragmentación socio-espacial y las políticas sociales en el área metropolitana de Buenos Aires (1990-2005). En Alicia Ziccardi (comp.), Procesos de urbanización de la pobreza y nuevas formas de exclusión social. Bogotá: Siglo del Hombre, CLACSO.

Soldano, D. (2012). Confinamientos e intercambios en una sociedad desigual. Una investigación sobre movilidad en la periferia del Gran Buenos Aires. En María Carman, Neiva Vieira y Ramiro Segura (orgs.), Segregación y diferencia en la ciudad. Quito: FLACSO.

Sznol, F. E. (2007). Geografía de la Resistencia. Protesta social, formas de apropiación y transformación del espacio urbano en la Argentina (1996-2006). Theomai, (15), 21-34.

Theodore, N., Peck, J. y Brenner, N. (2009). Urbanismo neoliberal: la ciudad y el imperio de los mercados. Temas Sociales SUR, 66, 1-11. http://www.sitiosur. cl/r.php?id=898

Tilly, C. (2000). Acción Colectiva. Cuadernos del CECYP, (6), 9-32.

Torres, F. (2011). Territorio y lugar: Potencialidades para el análisis de la constitución de sujetos políticos: El caso de un movimiento de desocupados en Argentina. Geograficando, 7(7), 209-238.

Vargas, V. (2009). La violencia de género: pistas para un análisis. En Ana Falú (ed.), Mujeres en la ciudad. De violencias y derechos (pp. 55-60). Santiago de Chile: Ediciones SUR, Red mujer y Hábitat de América Latina. 